\title{
REBASE-restriction enzymes and methylases
}

\author{
Richard J.Roberts and Dana Macelis \\ New England BioLabs, 32 Tozer Road, Beverly, MA 01915, USA
}

\section{INTRODUCTION}

The restriction enzyme database, REBASE, is a collection of information about restriction enzymes and methylases. Since the last description of the contents of REBASE (1), 265 new entries have been added including 8 new Type II enzymes: AclI, AA $\uparrow$ CGTT; Bce83I, CTTGAG (16/14); BscGI, CCCGT; BseRI, GAGGAG (10/8); Bsp1407I, TiGTACA; BspLU11I, A†CATGT; BsrDI, GCAATG (2/0) and SexAI A†CCWGGT. A complete list of these new enzymes can be found in Table $I$. A total of 2393 restriction enzymes is now known including 17 different Type I specificities, 188 different Type II specificities and 4 different Type III specificities. Table II contains a listing of all prototype restriction enzymes (Types I, II and III), together with their commercially available isoschizomers and neoschizomers that cleave at a position different from their prototype.

REBASE is updated daily. Each month, a set of REBASE data files are released publically and distributed to the scientific community, at no charge, via e-mail. They can also be retrieved by anonymous ftp from vent.neb.com (192.138.220.2). These data files are flat ASCII text files, many of which are designed specifically for use with a variety of software packages such as GCG, IGSuite, GENEPRO, Staden, DNA Strider, Pro-Cite, and PC/Gene. Other data files include: a complete set of references, including abstracts, to papers on restriction enzymes and methylases; a list of all commercial suppliers of restriction enzymes and methylases, complete with contact information for each and a list of enzymes currently being sold. New data files are constantly being added and each release of REBASE includes a monthly release note indicating that the files at the $\mathrm{ftp}$ site have been updated, and listing new enzymes, newly available formats, enzyme name changes, etc. To join the mailing list or for more information, send a request to R.J.Roberts via e-mail to roberts@neb.com, telephone (508)927-3382 or Fax (508)921-1527.

Since last year, International Biotechnologies Inc. (IBI) and Serva have discontinued selling restriction enzymes or methylases. Listings have been added for Appligene and Angewandte Gentechnologie Systeme.

Several enzyme names have been changed recently. Bsp1236I (FnuDII) has become Bsh1236I. IspI (Fnu4HI) is now ItaI. Also it was discovered that the name MthTI had been used for two different enzymes. The original enzyme, MthTI (AsuI), is now called MthBI. The current enzyme, MthTI (HaeIII), is a new enzyme reported by Nolling and de Vos, J. Bacteriol. 174: 5719-5726 (1992). Two previously unidentified bacteria have been identified, leading to name changes of $U b a 1269$ I to Mva1269I (BsmI) and Uba1285I to Bsh1285I (McrI).

In forming these Tables, all endonucleases cleaving DNA at a specific sequence have been considered to be restriction enzymes, although in most cases there is no direct genetic evidence for the presence of a restriction modification system. The endonucleases are named in accordance with the proposal of Smith and Nathans (2).

\section{ACKNOWLEDGEMENTS}

Special thanks are due to the many individuals who have so kindly communicated their unpublished results for inclusion in this compilation. Work from the authors' laboratory is supported by the N.I.H. (GM40537).

\section{REFERENCES}

1. Roberts, R.J. and Macelis D. Nucl. Acids Res. 20: 2167-2180 (1992).

2. Smith, H.O. and Nathans, D. J. Mol. Biol. 81: 419-423 (1973).

3. Degtyarev, S.K., Abdurashitov, M.A., Kolyhalov, A.A., Rechkunova, N.I. Nucl. Acids Res. 20: 3787 (1992).

4. Rutkowska, S.M., Skowron, P.M., Podhajska, A.J. Unpublished observations.

5. Repin, V.E. Unpublished observations.

6. Chiura, H.X., Kamiyama, T., Hirano, H., Futagami, M., Watahiki, M., Kobayashi, K., Simidu, U., Takagi, J. Nucl. Acids Res. 20: 1996 (1992).

7. Degtyarev, S.K., Kolyhalov, A.A., Rechkunova, N.I., Abdurashitov, M.A. Nucl. Acids Res. 20: 3789 (1992).

8. Choudhry, S., Malik, K., Sohail, A. Unpublished observations.

9. Frey, B., Kaluza, K., Auer, J., Stratidakis, I., Rina, M., Bouriotis, V., Schmitz, G. Nucl. Acids Res. 20: 3782 (1992).

10. Kolesnikov, V.A., Kovalenko, S.P., Repin, V.E., Protopopov, M.O., Karginov, V.A. Unpublished observations.

11. Lange, C., Noyer-Weidner, M., Trautner, T.A., Weiner, M., Zahler, S.A. Gene 100: 213-218 (1991).

12. Matvienko, N.N., Kramarov, V.M., Ivanov, L.Y., Matvienko, N.I. Nucl. Acids Res. 20: 1803 (1992).

13. Wu, S.Y., Lee, K.F., Kam, K.M.,Shaw, P.C. Unpublished observations.

14. Janulaitis, A., Kazlauskiene, R., Trinkunaite, L., Kiuduliene, L., Maneliene, Z., Petrusyte, M., Butkus, V. Unpublished observations.

15. Pogge von Strandmann, R., Stadtler, R., Walter, T., Frey, B., Kaluza, K., Hengstenberg, W., Schmitz, G. Nucl. Acids Res. 20: 4664 (1992).

16. Zhao, Z.-H., Yung, M.-H., Cui, T., Wang, Y.-Z., Shaw, P.-C. Nucl. Acids Res. 20: 1156 (1992).

17. Schoenfeld, T. Unpublished observations.

18. Rina, M., Dialektakis, D., Clark, D., Pagomenou, M., Bouriotis, V. Nucl. Acids Res. 20: 1807 (1992).

19. Polisson, C. Unpublished observations.

20. Kramarov, V.M. Unpublished observations.

21. Kovalevskaya, N.P., Zheleznaya, L.A., Matvienko, N.I. Bioorg. Khim. 18: 1473-1477 (1992).

22. Matvienko, N.N., Zeleznaja, L.A., Matvienko, N.I. Nucl. Acids Res. 21: 1495 (1993).

24. Saboohi, N., Malik, K., Sohail, A. Unpublished observations.

25. Moriya, S., Yanagawa, S., Aoki, N., Iwabuchi, M., Inoue, T., Ando, T. Nucl. Acids Res. 20: 3781 (1992).

26. Janulaitis, A.A., Bitinaite, J., Jagelivicius, M., Naureckiene, S., Vaitkevicius, D., Maneliene, Z., Kiuduliene, L., Butkus, V. Unpublished observations.

27. Janulaitis, A., Petrusyte, M., Maneliene, Z., Capskaya, L., Kiuduliene, L., Butkus, V. Unpublished observations. 
28. Janulaitis, A., Lazareviciute, L., Bitinaite, J., Maneliene, Z., Kiuduliene, L., Butkus, V. Unpublished observations.

29. Lee, K.-F., Shi, S.-D., Kam, K.M., Shaw, P.C. Nucl. Acids Res. 20: 921 (1992).

30. Chen, $Z$. Unpublished observations.

31. Chen, Z., Morgan, R. Unpublished observations.

32. Lobos, C., Vasquez, C. Biochim. Biophys. Acta 1171: 295-298 (1993).

33. Clark, D. Unpublished observations.

34. Shapovalova, N.I., Ivanov, L.Yu., Matvienko, N.I. Bioorg. Khim. 18: 1186-1189 (1992)

35. Janulaitis, A., Rudokas, K., Petrusyte, M., Maneliene, Z., Norgeliene, D., Vonseviciene, E., Kiuduliene, L., Butkus, V. Unpublished observations.

36. Repin, V.E., Burtseva, L.I., Burlak, V.A., Trusova, S.I. Mol. Genet. Mikrobiol. Virusol. 0: 20-22 (1991).

37. Azizbekyan, R.R., Rebentish, B.A., Netyksa, E.M., Bychkova, M.A., Bolotin, A.P. Mol. Genet. Mikrobiol. Virusol. 0: 13-15 (1992).

38. Mushtaq, R., Naeem, S., Ahmed, M., Sohail, A., Riazuddin, S. Unpublished observations.

39. Azeddoug, H., Reysset, G., Sebald, M. FEMS Microbiol. Lett. 95: 133-136 (1992).

40. Zhang, Y., Nelson, M., Nietfeldt, J.W., Burbank, D.E., Van Etten, J.L. Nucl. Acids Res. 20: 5351-5356 (1992).

41. Zhang, Y., Nelson, M., Van Etten, J.L. Nucl. Acids Res. 20: 1637-1642 (1992).

42. Mermelstein, L.D., Welker, N.E., Bennett, G.N., Papoutsakis, E.T BioTechnology 10: 190-195 (1992).

43. Chan, H.Y., Chan, Y.C., Kam, K.M., Shaw, P.C. Unpublished observations.

44. Chan, Y.C., Kam, K.M.,Shaw, P.C. Unpublished observations.

45. Janulaitis, A., Krikstulyte, V., Trinkunaite, L., Maneliene, Z., Kiudiliene, L., Petrusyte, M., Butkus, V. Unpublished observations.

46. Denjmuchametov, M.M., Ruban, N.M., Zakharova, M.V., Beletzkaja, I.V., Kravetz, A.N., Solonin, A.S. Nucl. Acids Res. 20: 1992 (1992).

47. Pertzev, A.V., Ruban, N.M., Zakharova, M.V., Beletzkaja, I.V., Petrov, S.I., Kravetz, A.N., Solonin, A.S. Nucl. Acids Res. 20: 1991 (1992).

48. Marinus, M.G., Morris, N.R. J. Bacteriol. 114: 1143-1150 (1973).

49. May, M.S., Hattman, S. J. Bacteriol. 122: 129-138 (1975).

50. Geier, G.E., Modrich, P. J. Biol. Chem. 254: 1408-1413 (1979).

51. Hattman, S., Brooks, J.E., Masurekar, M. J. Mol. Biol. 126: 367-380 (1978).

52. Lacks, S., Greenberg, B. J. Mol. Biol. 114: 153-168 (1977)

53. Kravetz, A.N., Zakharova, M.V., Beljetzkaja, I.V., Pertzev, A.V., Spivak, O.I. Solonin, A.S. Nucl. Acids Res. 21: 1501 (1993).

54. Kravetz, A.N., Zakharova, M.V., Beljetzkaja, I.V., Pertzev, A.V., Spivak O.I., Solonin, A.S. Unpublished observations.

55. Nyengaard, N., Josephsen, J. Unpublished observations.

56. Nyengaard, N., Vogensen, F.K., Josephsen, J. Unpublished observations.
57. Thomm, M. Unpublished observations.

58. Nolling, J., de Vos, W.M. Nucl. Acids Res. 20: 5047-5052 (1992).

59. Nelson, M. Unpublished observations.

60. Sosnovtsev, S.V., Dedkov, V.S., Rechkunova, N.I., Zernov, I.P., Degtyarev, S.Kh. Izv. Sib. Otd. Akad. Nauk SSSR 0: 66-67 (1991)

61. Rina, M., Tzanodaskalaki, M., Karagouni, A., Pagomenou, M., Bouriotis, V. Nucl. Acids Res. 20: 1806 (1992).

62. Shankar, S., Tyagi, A.K. Nucl. Acids Res. 20: 2890 (1992).

63. Shankar, S., Tyagi, A.K. Nucl. Acids Res. 20: 2891 (1992).

64. Labbe, D., Holtke, H.J., Lau, P.C.K. Mol. Gen. Genet. 224: 101-110 (1990).

65. Piechula, S., Kur, J., Podhajska, A.J. Unpublished observations.

66. Piechula, S., Kur, J., Bielawski, K., Podhajska, A.J. Nucl. Acids Res. 20: 6738 (1992).

68. Kravetz, A.N., Pertzev, A.V., Zakharova, M.V., Beletzkaja, I.V., Churkina, L.N., Solonin, A.S. Unpublished observations.

69. Janulaitis, A.,, Steponaviciene, D., Petrusyte, M., Maneliene, Z., Norgeliene, D., Vonseviciene, E., Kiuduliene, L., Butkus, V. Unpublished observations.

70. Naeem, S., Mushtaq, R., Riazuddin, S. Unpublished observations.

71. Morrison, M., Mackie, R.I., White, B.A. Gene 111: 105-108 (1992).

72. Morrison, M., Mackie, R.I., White, B.A. Austral. Microbiol. 0: 301-303 (1992).

73. Pristas, P., Kutejova, E., Godany, A., Javorsky, P., Vanat, I. Unpublished observations.

74. Molnar, A., Geck, P., Orosz, A., Kulcsar, P., Nasz, I. Acta Microbiol. Hungarica 38: 55-60 (1991).

75. Geck, P., Molnar, A., Nasz, I. Acta Microbiol. Hungarica 38: 47-53 (1991).

76. Rutkowska, S.M., Skowron, P.M., Bielawski, K., Podhajska, A.J. Unpublished observations.

77. Pristas, P., Godany, A., Sevcikova, B., Oktavcova, B., Farkasovska, J. Nucl. Acids Res. 20: 4364 (1992).

78. Nomura, Y., Ito, H., Sagawa, H., Kotani, H., Kimizuka, F., Nakajima, K. Unpublished observations.

79. Frey, B. Unpublished observations.

80. Saboohi, N., Sohail, A. Unpublished observations.

81. Saboohi, N., Mushtaq, R., Sohail, A. Unpublished observations.

82. Rina, M., Tzanodaskalaki, M., Karagouni, A., Pagomenou, M., Bouriotis, V. Nucl. Acids Res. 20: 1808 (1992)

83. Knoblich, I.M., Sellmann, E., Kaluza, K., Frey, B., Auer, J., Schmitz, G.G., Westermann, P. Nucl. Acids Res. 20: 2378 (1992).

84. Janulaitis, A., Krikstulyte, V., Trinkunaite, L., Maneliene, Z., Kiuduliene, L., Petrusyte, M., Butkus, V. Unpublished observations.

85. Torsti, A-M., Korpela, J., Hjorleifsdottir, S., Tenkanen, T., Pitkanen, K. Mattila, P., Kristjansson, J. Unpublished observations.

86. Janulaitis, A. Unpublished observations.

Table 1.

\begin{tabular}{|c|c|c|c|c|}
\hline Microorganism & Source & Enzyme $^{1}$ & Sequence $^{2}$ & Reference \\
\hline Acinetobacter calcoaceticus M4 & S.K. Degtyarev & AclI & AAICGTT & 3 \\
\hline $\begin{array}{l}\text { Actinomyces violaceoniger } \\
\text { cristalomycini }\end{array}$ & A.J. Podhajska & AvcI (Sau96I) & GIGNCC & 4 \\
\hline Alcaligenes aquamarines 559 & V.E. Repin & AaqI (ApaLI) & GTGCAC & 5 \\
\hline Alcaligenes species MD1 & H.X. Chiura & AspMDI (Mbol) & IGATC & 6 \\
\hline Arthrobacter citreus 310 & S.K. Degtyarev & AcsI (ApoI) & R†AATTY & 7 \\
\hline Arthrobacter picolinophilus & CAMB 2604 & ApiI (PstI) & CTGCAIG & 8 \\
\hline Aureobacterium species & K. Kaluza & AspEI (Eam1105I) & GACNNNINNGTC & 9 \\
\hline Bacillus Species N & A.A. Janulaitis & BseNI (Bsrl) & ACTGG $(1 /-1)$ & 10 \\
\hline Bacillus amyloliquefaciens phage $\mathrm{H} 2$ & T.A. Trautner & M.H2I (HaeIII) & GGCC & 11 \\
\hline Bacillus cereus 83 & N.I. Matvienko & Bce83I & CTTGAG (16/14) & 12 \\
\hline Bacillus circulans 29 & V.E. Repin & Bci29I (ClaI) & ATtCGAT & 5 \\
\hline \multirow[t]{2}{*}{ Bacillus coagulans 102} & V.E. Repin & Bco102I (BclI) & TGATCA & 5 \\
\hline & & Bco102II (BbvII) & GAAGAC & 5 \\
\hline Bacillus coagulans 116 & V.E. Repin & Bco116I (Ksp632I) & CTCTTC (1/4) & 5 \\
\hline Bacillus coagulans 118 & V.E. Repin & Bco118I (Cfr10I) & RICCGGY & 5 \\
\hline Bacillus coagulans 163 & V.E. Repin & Bco163I (Sfel) & CTRYAG & 5 \\
\hline Bacillus coagulans 27 & V.E. Repin & Bco27I (HpaII) & CtCGG & 5 \\
\hline Bacillus coagulans 5 & V.E. Repin & Bco5I (Ksp632I) & CTCTTC $(1 / 4)$ & 5 \\
\hline Bacillus coagulans 6 & V.E. Repin & Bco6I (MstI) & TGCGCA & 5 \\
\hline Bacillus coagulans 63 & V.E. Repin & Bco63I (BsaBI) & GATNNNNATC & 5 \\
\hline Bacillus licheniformis HK & P.C. Shaw & BliHKI (Saul) & CC†TNAGG & 13 \\
\hline Bacillus megatherium RFL1390 & A.A. Janulaitis & Bme1390I (ScrFI) & CC†NGG & 14 \\
\hline
\end{tabular}


Nucleic Acids Research, 1993, Vol. 21, No. 133127

Table 1. (continued)

\begin{tabular}{|c|c|c|c|c|}
\hline Bacillus pumilus & G. Schmitz & BpuAI (BbvII) & GAAGAC (2/6) & 15 \\
\hline Bacillus pumilus & P.C. Shaw & BpuB5I (SplI) & CtGTACG & 16 \\
\hline Bacillus schlegelii 107 & V.E. Repin & Bsc107I (BsiYI) & CCNNNNNNNGG & 5 \\
\hline Bacillus schlegelii 4 & V.E. Repin & Bsc4I (BsiYI) & CCNNNNNNNGG & 5 \\
\hline Bacillus species & T. Schoenfeld & $B s c 911$ (BbvII) & GAAGAC $(2 / 6)$ & 17 \\
\hline Bacillus species & V. Bouriotis & BseCI (ClaI) & ATICGAT & 18 \\
\hline Bacillus species 16 & V.E. Repin & Bse16I (EcoRII) & CC†WGG & 5 \\
\hline Bacillus species 17 & V.E. Repin & Bse17I (EcoRII) & CCiWGG & 5 \\
\hline Bacillus species $1 \mathrm{H}$ & D. Clark & BscGI & CCCGT & 19 \\
\hline Bacillus species 23 & V.E. Repin & Bse23I (BsiYI) & CCNNNNNNNGG & 5 \\
\hline Bacillus species 24 & V.E. Repin & Bse24I (EcoRII) & CCiWGG & 5 \\
\hline Bacillus species 59 & V.E. Repin & Bse59I (BstEII) & GGTNACC & 5 \\
\hline Bacillus species 64 & V.E. Repin & Bse64I (BstEII) & GGTNACC & 5 \\
\hline Bacillus species 8 & V.E. Repin & Bse8I (BsaBI) & GATNNNNATC & 5 \\
\hline Bacillus species 9A & D. Clark & BscJI (BstXI) & CCANNNNNNTGG & 19 \\
\hline Bacillus species A & D. Clark & BscHI (BsrI) & ACTGG & 19 \\
\hline Bacillus species $\mathbf{K}$ & V.M. Kramarov & BspKI (HaeIII) & GGICC & 20 \\
\hline Bacillus species LS2 & N.I. Matvienko & BspLS2I (SduI) & GDGCHIC & 21 \\
\hline \multirow[t]{2}{*}{ Bacillus species LU11 } & N.I. Matvienko & BspLU11I & A†CATGT & 22 \\
\hline & & BspLU11II (XbaI) & TCTAGA & 22 \\
\hline Bacillus species M90 & V.M. Kramarov & BspM90I (Snal) & GTAITAC & 20 \\
\hline Bacillus species $\mathbf{N}$ & CAMB 2677 & BspNI (EcoRII) & CC†WGG & 24 \\
\hline Bacillus species $0-4$ & ATCC 21536 & Bsp04I (PvuII) & CAGICTG & 25 \\
\hline Bacillus species $\mathbf{Q}$ & V.E. Repin & BseQI (HaeIII) & GGICC & 5 \\
\hline Bacillus species $\mathrm{Z}$ & V.E. Repin & BseZI (Ksp632I) & CTCTTC $(1 / 4)$ & 5 \\
\hline Bacillus sphaericus RFL1236 & A.A. Janulaitis & Bsh1236I (FnuDII) & CGICG & 26 \\
\hline Bacillus sphaericus RFL1285 & A.A. Janulaitis & Bsh1285I (McrI) & CGRYICG & 27 \\
\hline Bacillus sphaericus RFL1365 & A.A. Janulaitis & Bsh1365I (BsaBI) & GATNN $I N N A T C$ & 28 \\
\hline Bacillus stearothermophilus & P.C. Shaw & BsiHKAI (HgiAI) & GWGCWIC & 29 \\
\hline Bacillus stearothermophilus 100 & V.E. Repin & Bst100I (EcoRII) & CC†WGG & 5 \\
\hline Bacillus stearothermophilus 11 & V.E. Repin & Bst11I (BsrI) & ACTGG $(1 /-1)$ & 5 \\
\hline Bacillus stearothermophilus 12 & V.E. Repin & Bst12I (BbvI) & GCAGC & 5 \\
\hline \multirow[t]{2}{*}{ Bacillus stearothermophilus 1473} & Z. Chen & Bst1473I (BetI) & WCCGGW & 30 \\
\hline & & Bst 1473II (HaeII) & RGCGCY & 30 \\
\hline Bacillus stearothermophilus 2 & V.E. Repin & Bst2I (EcoRII) & CCIWGG & 5 \\
\hline Bacillus stearothermophilus 38 & V.E. Repin & Bst38I (EcoRII) & CC†WGG & 5 \\
\hline Bacillus stearothermophilus $4 \mathrm{Q}$ & Z. Chen & Bst4QI (AvaII) & GGWCC & 30 \\
\hline \multirow[t]{2}{*}{ Bacillus stearothermophilus $7 Q$} & Z. Chen & Bst7QI (Aval) & CYCGRG & 30 \\
\hline & & Bst7QII (BstNI) & CCWGG & 30 \\
\hline Bacillus stearothermophilus C98 & Z. Chen & Bst98I (Ksp632I) & СТCTTC & 30 \\
\hline Bacillus stearothermophilus CPW548 & Z. Chen & BsmPI (HgiAl) & GWGCWC & 30 \\
\hline Bacillus stearothermophilus Cpw230 & Z. Chen & BsaXI & $?$ & 30 \\
\hline Bacillus stearothermophilus Cpw514 & Z. Chen & BsaZI (HpaII) & CCGG & 30 \\
\hline \multirow[t]{2}{*}{ Bacillus stearothermophilus D170 } & Z. Chen & Bst170I (BsrGI) & TGTACA & 30 \\
\hline & & Bst170II (HindIII) & AAGCTT & 30 \\
\hline Bacillus stearothermophilus D70 & Z. Chen & BsrDI & GCAATG $(2 / 0)$ & 30 \\
\hline Bacillus stearothermophilus E505 & Z. Chen & BsmEI (PleI) & GAGTC & 30 \\
\hline Bacillus stearothermophilus F & Z. Chen & BsmFI (FinI) & GGGAC (10/14) & 31 \\
\hline Bacillus stearothermophilus F6 & Z. Chen & BssFI (Fnu4HI) & GCNGC & 30 \\
\hline \multirow[t]{2}{*}{ Bacillus stearothermophilus GR75 } & Z. Chen & BsrGI (Bsp 14071) & TIGTACA & 30 \\
\hline & & BsrGII & $?$ & 30 \\
\hline Bacillus stearothermophilus $\mathbf{2 2 4}$ & Z. Chen & Bst224I (StyI) & CCWWGG & 30 \\
\hline Bacillus stearothermophilus LV & C. Vasquez & BstLVI (ClaI) & ATCGAT & 32 \\
\hline Bacillus stearothermophilus Lipari 28 & D. Clark & BsoFI (BsrI) & ACTGG & 33 \\
\hline \multirow[t]{2}{*}{ Bacillus stearothermophilus Lipari 29} & D. Clark & BsoGI (EcoRII) & CCWGG & 33 \\
\hline & & BsoGII & ? & 33 \\
\hline Bacillus stearothermophilus M16 & Z. Chen & Bst16I (HaeII) & RGCGCY & 30 \\
\hline Bacillus stearothermophilus M6 & N.I. Matvienko & BstM6I (EcoRII) & CCtWGG & 34 \\
\hline Bacillus stearothermophilus N365 & Z. Chen & BsmNI (SfaNI) & GCATC & 30 \\
\hline Bacillus stearothermophilus P158 & Z. Chen & Bst 158I (Ksp632I) & СTCTTC & 30 \\
\hline Bacillus stearothermophilus RFL1407 & A.A. Janulaitis & Bsp1407i & TIGTACA & 35 \\
\hline Bacillus stearothermophilus SR65 & Z. Chen & BsaUI (BbvI) & GCAGC & 30 \\
\hline Bacillus stearothermophilus SR65 & Z. Chen & BsoSI (Scal) & AGTACT & 30 \\
\hline Bacillus stearothermophilus V35 & Z. Chen & BsrVI (BbvI) & GCAGC & 30 \\
\hline Bacillus stearothermophilus W493 & Z. Chen & BsrWI (BinI) & GGATC & 30 \\
\hline Bacillus stearothermophilus X173 & Z. Chen & BsrXI (XbaI) & TCTAGA & 30 \\
\hline Bacillus subtilis 23 & V.M. Kramarov & Bsu23I (BspMII) & TICCGGA & 20 \\
\hline Bacillus subtilis 54 & V.M. Kramarov & Bsu54I (AsuI) & GIGNCC & 20 \\
\hline Bacillus thuringiensis 33 & V.E. Repin & Btu33I (MboI) & GATC & 36 \\
\hline Bacillus thuringiensis 36 & V.E. Repin & Btu36I (MboI) & GATC & 36 \\
\hline Bacillus thuringiensis 37 & V.E. Repin & Btu37I (MboI) & GATC & 36 \\
\hline Bacillus thuringiensis 39 & V.E. Repin & Btu39I (MboI) & GATC & 36 \\
\hline Bacillus thuringiensis 41 & V.E. Repin & Btu41I (MboI) & GATC & 6 \\
\hline
\end{tabular}


3128 Nucleic Acids Research, 1993, Vol. 21, No. 13

Table 1. (continued)

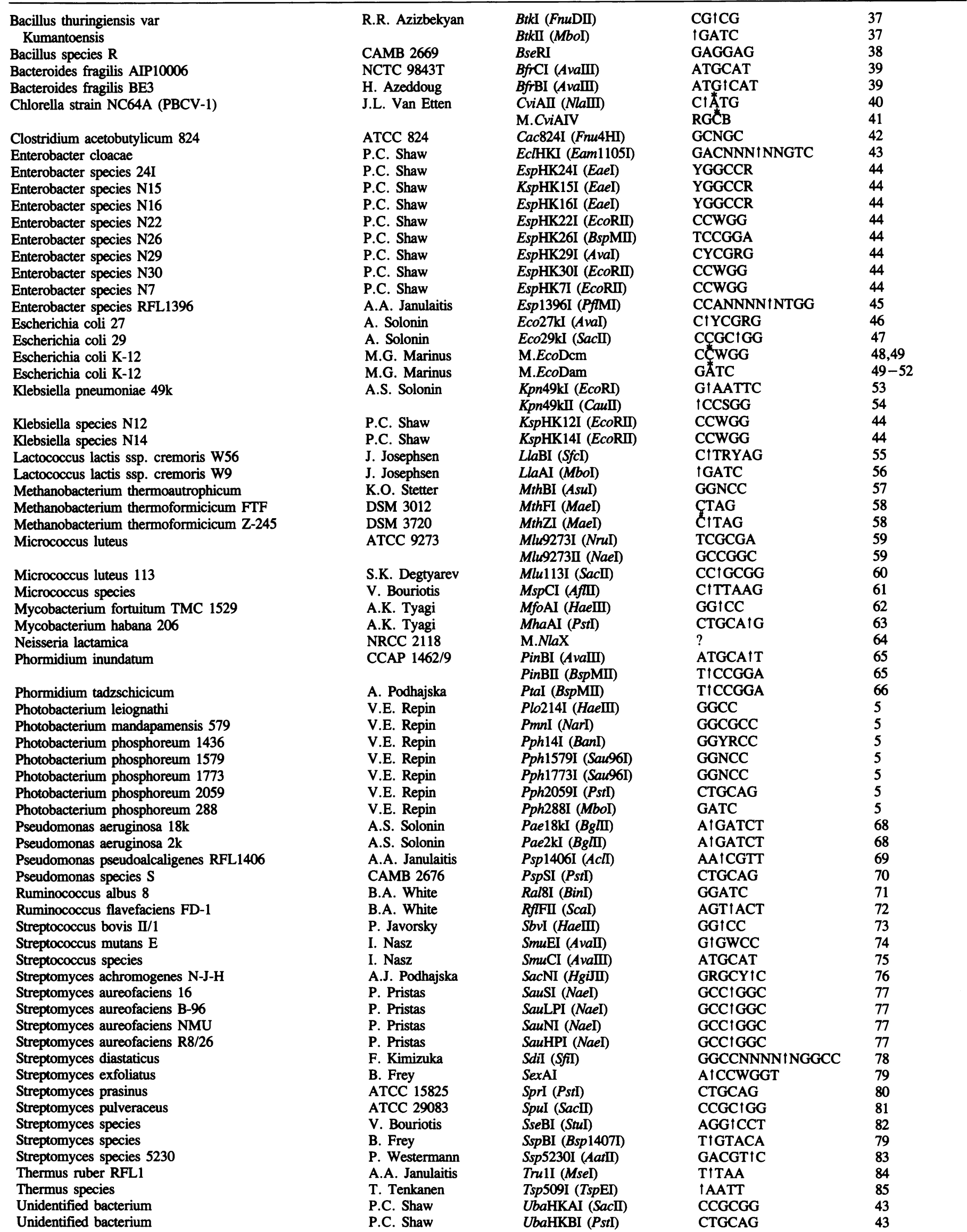


Nucleic Acids Research, 1993, Vol. 21, No. 133129

Table 1. (continued)

Unidentified bacterium RFL1355 Unidentified bacterium RFL1357 Unidentified bacterium RFL1362 Unidentified bacterium RFL1363 Unidentified bacterium RFL1364

Unidentified bacterium RFL1366

Unidentified bacterium RFL1367 Unidentified bacterium RFL1368 Unidentified bacterium RFL1369 Unidentified bacterium RFL1370 Unidentified bacterium RFL1371 Unidentified bacterium RFL1372 Unidentified bacterium RFL1373 Unidentified bacterium RFL1374 Unidentified bacterium RFL1375 Unidentified bacterium RFL1376 Unidentified bacterium RFL1377 Unidentified bacterium RFL1378 Unidentified bacterium RFL1379 Unidentified bacterium RFL1380 Unidentified bacterium RFL1381 Unidentified bacterium RFL1382 Unidentified bacterium RFL1383 Unidentified bacterium RFL1384 Unidentified bacterium RFL1385 Unidentified bacterium RFL1386 Unidentified bacterium RFL1387 Unidentified bacterium RFL1388 Unidentified bacterium RFL1389 Unidentified bacterium RFL1391 Unidentified bacterium RFL1392 Unidentified bacterium RFL1393 Unidentified bacterium RFL1394 Unidentified bacterium RFL1395 Unidentified bacterium RFL1397 Unidentified bacterium RFL1398 Unidentified bacterium RFL1399 Unidentified bacterium RFL1400 Unidentified bacterium RFL1401 Unidentified bacterium RFL1402 Unidentified bacterium RFL1403 Unidentified bacterium RFL1404 Unidentified bacterium RFL1405 Unidentified bacterium RFL1408

Unidentified bacterium RFL1409 Unidentified bacterium RFL1410 Unidentified bacterium RFL1411 Unidentified bacterium RFL1412 Unidentified bacterium RFL1413 Unidentified bacterium RFL1414 Unidentified bacterium RFL1415

Unidentified bacterium RFL1416

Unidentified bacterium RFL1417

Unidentified bacterium RFL1418

Unidentified bacterium RFL1419

Unidentified bacterium RFL1420

Unidentified bacterium RFL1421

Unidentified bacterium RFL1422

Unidentified bacterium RFL1423

Unidentified bacterium RFL1424

Unidentified bacterium RFL1425

Unidentified bacterium RFL1426

Unidentified bacterium RFL1427

Unidentified bacterium RFL1428

Unidentified bacterium RFL1429

Unidentified bacterium RFL1430

Unidentified bacterium RFL1431

Unidentified bacterium RFL1432

Unidentified bacterium RFL1433

Unidentified bacterium RFL1434

Unidentified bacterium RFL1435

\begin{abstract}
A.A. Janulaitis
A.A. Janulaitis

A.A. Janulaitis

A.A. Janulaitis

A.A. Janulaitis

A.A. Janulaitis
\end{abstract}

A.A. Janulaitis

A.A. Janulaitis

A.A. Janulaitis

A.A. Janulaitis

A.A. Janulaitis

A.A. Janulaitis

A.A. Janulaitis

A.A. Janulaitis

A.A. Janulaitis

A.A. Janulaitis

A.A. Janulaitis

A.A. Janulaitis

A.A. Janulaitis

A.A. Janulaitis

A.A. Janulaitis

A.A. Janulaitis

A.A. Janulaitis

A.A. Janulaitis

A.A. Janulaitis

A.A. Janulaitis

A.A. Janulaitis

A.A. Janulaitis

A.A. Janulaitis

A.A. Janulaitis

A.A. Janulaitis

A.A. Janulaitis

A.A. Janulaitis

A.A. Janulaitis

A.A. Janulaitis

A.A. Janulaitis

A.A. Janulaitis

A.A. Janulaitis

A.A. Janulaitis

A.A. Janulaitis

A.A. Janulaitis

A.A. Janulaitis

A.A. Janulaitis

A.A. Janulaitis

A.A. Janulaitis

A.A. Janulaitis

A.A. Janulaitis

A.A. Janulaitis

A.A. Janulaitis

A.A. Janulaitis

A.A. Janulaitis

A.A. Janulaitis

A.A. Janulaitis

A.A. Janulaitis

A.A. Janulaitis

A.A. Janulaitis

A.A. Janulaitis

A.A. Janulaitis

A.A. Janulaitis

A.A. Janulaitis

A.A. Janulaitis

A.A. Janulaitis

A.A. Janulaitis

A.A. Janulaitis

A.A. Janulaitis

A.A. Janulaitis

A.A. Janulaitis

A.A. Janulaitis

A.A. Janulaitis

A.A. Janulaitis

A.A. Janulaitis

Uba1355I (HpaII)
Uba1357I (HgiJII)
Uba1362I (SduI)
Uba1363I (HgiJII)
Uba1364I (SacII)
Uba1366I (MboI)
Uba1366II (ClaI)
Uba1367I (AvaIII)

Uba1367I (AvaliI)

Uba1368I (ApaI)

Uba1369I (SacII)

Uba1370I (CauII)

Uba1371I (StuI)

Uba1372I (CauII)

Uba1373I (AvaII)

Uba1374I (AflII)

Uba1375I (BspMII)

Uba1376I (CauII)

Uba1377I (HaeIII)

Uba1378I (CauII)

Uba1379I (ClaI)

Uba1380I (ClaI)

Uba1381I (AcyI)

Uba1382I (BsmI)

Uba1383I (BamHI)

Uba1384I (AvaIII)

Uba1385I (AsuII)

Uba1386I (NruI)

Uba1387I (ApaLI)

Uba1388I (HaeIII)

Uba1389I (CauII)

Uba1391I (ScrFI)

Uba1392I (HaeIII)

Uba1393I (SmaI)

Uba1394I (ClaI)

Uba1395I (HaeIII)

Uba1397I (XhoI)

Uba1398I (BamHI)

Uba1399I (PstI)

Uba1400I (EcoRV)

Uba1401I (CauII)

Uba1402I (BamHI)

Uba1403I (StuI)

Uba1404I (FnuDII)

Uba1405I (FnuDII)

Uba1408I (HaeIII)

Uba1408II (HpaI)

Uba1409I (HgiJII)

Uba1410I (EcoRII)

Uba1411I (PstI)

Uba1412I (ClaI)

Uba1413I (AvaII)

Uba1414I (BamHI)

Uba1415I (BsmI)

Uba1416I (ClaI)

Uba1417I (PstI)

Uba1418I (HaeIII)

Uba1419I (StuI)

Uba1420I (AflII)

Uba1421I (HgiJII)

Uba1422I (HaeIII)

Uba1423I (CauII)

Uba1424I (CauII)

Uba1425I (BspMII)

Uba1426I (AflII)

Uba1427I (ClaI)

Uba1428I (EcoRII)

Uba1429I (HaeIII)

Uba1430I (ClaI)

Uba1431I (BclI)

Uba1432I (XhoII)

Uba1433I (AluI)

Uba1434I (SecI)

Uba1435I (HindIII)

CCGG

GDGCHC

GRGCYC 86

CCGCGG 86

GATC

ATCGAT

ATGCAT

GGGCCC

CCGCGG

CCSGG

AGGCCT

CCSGG

GGWCC

CTTAAG

TCCGGA

CCSGG

GGCC

CCSGG

ATCGAT

ATCGAT

GRCGYC

GAATGC

GGATCC

ATGCAT

TTCGAA

TCGCGA

GTGCAC

GGCC

CCSGG

CCNGG

GGCC

CCCGGG

ATCGAT

GGCC

CTCGAG

GGATCC

CTGCAG

GATATC

CCSGG

GGATCC

AGGCCT

CGCG

CGCG

GGCC

GTTAAC

GRGCYC

CCWGG

CTGCAG

ATCGAT

GGWCC

GGATCC

GAATGC

ATCGAT

CTGCAG

GGCC

AGGCCT

CTTAAG

GRGCYC

GGCC

CCSGG

CCSGG

TCCGGA

CTTAAG

ATCGAT

CCWGG

GGCC

ATCGAT

TGATCA

RGATCY

AGCT

CCNNGG

AAGCTT 
3130 Nucleic Acids Research, 1993, Vol. 21, No. 13

Table 1. (continued)

\begin{tabular}{|c|c|c|c|c|}
\hline Unidentified bacterium RFL1436 & A.A. Janulaitis & Uba1436I (AvaI) & CYCGRG & 86 \\
\hline Unidentified bacterium RFL1437 & A.A. Janulaitis & Uba1437I (GsuI) & CTGGAG & 86 \\
\hline Unidentified bacterium RFL1438 & A.A. Janulaitis & Uba1438I (AvaII) & GGWCC & 86 \\
\hline Unidentified bacterium RFL1439 & A.A. Janulaitis & Uba1439I (HpaII) & CCGG & 86 \\
\hline Unidentified bacterium RFL1440 & A.A. Janulaitis & Uba1440I (AvaI) & CYCGRG & 86 \\
\hline Unidentified bacterium RFL1441 & A.A. Janulaitis & Uba1441I (AluI) & AGCT & 86 \\
\hline Unidentified bacterium RFL1442 & A.A. Janulaitis & Uba1442I (SecI) & CCNNGG & 86 \\
\hline Unidentified bacterium RFL1443 & A.A. Janulaitis & Uba1443I (AflII) & CTTAAG & 86 \\
\hline Unidentified bacterium RFL1444 & A.A. Janulaitis & Uba1444I (GsuI) & CTGGAG & 86 \\
\hline Unidentified bacterium RFL1445 & A.A. Janulaitis & Uba1445I (NlaIV) & GGNNCC & 86 \\
\hline Unidentified bacterium RFL1446 & A.A. Janulaitis & Uba1446I (FnuDII) & CGCG & 86 \\
\hline Unidentified bacterium RFL1447 & A.A. Janulaitis & Uba1447I (BclI) & TGATCA & 86 \\
\hline Unidentified bacterium RFL1448 & A.A. Janulaitis & Uba1448I (XhoI) & CTCGAG & 86 \\
\hline Unidentified bacterium RFL1449 & A.A. Janulaitis & Uba1449I (HaeIII) & GGCC & 86 \\
\hline Unidentified bacterium RFL1450 & A.A. Janulaitis & Uba1450I (HaeIII) & GGCC & 86 \\
\hline Unidentified bacterium RFL1451 & A.A. Janulaitis & Uba1451I (ClaI) & ATCGAT & 86 \\
\hline Unidentified bacterium RFL1452 & A.A. Janulaitis & Uba1452I (AsuII) & TTCGAA & 86 \\
\hline Unidentified bacterium RFL1453 & A.A. Janulaitis & Uba1453I (ClaI) & ATCGAT & 86 \\
\hline Unidentified microorganism 5T & V.E. Repin & Umi5I (Aval) & CYCGRG & 5 \\
\hline Unidentified microorganism $7 \mathrm{~T}$ & V.E. Repin & Umi71 (BclI) & TGATCA & 5 \\
\hline Vibrio fischerii 1246 & V.E. Repin & Vfil (AflII) & CTTAAG & 5 \\
\hline Vibrio harveyi 1168 & V.E. Repin & Vha1168I (HaeIII) & GGCC & 5 \\
\hline Vibrio harveyi 44 & V.E. Repin & Vha44I $(M b o I)$ & GATC & 5 \\
\hline Vibrio species 2246 & V.E. Repin & Vsp2246I (BanI) & GGYRCC & 5 \\
\hline
\end{tabular}

1. When two enzymes recognize the same sequence, i.e., are isoschizomers, the prototype (i.e., the first example isolated) is indicated in parentheses.

2. Recognition sequence representations use the standard abbreviations (Eur. J. Biochem. 150: 1-5, 1985) to represent ambiguity.

$$
\begin{aligned}
& \mathbf{R}=\mathbf{G} \text { or } \mathbf{A} \\
& \mathrm{Y}=\mathrm{C} \text { or } \mathrm{T} \\
& M=A \text { or } C \\
& \mathbf{K}=\mathbf{G} \text { or } \mathbf{T} \\
& \mathbf{S}=\mathbf{G} \text { or } \mathbf{C} \\
& \mathbf{W}=\mathbf{A} \text { or } \mathbf{T} \\
& B=\operatorname{not} A(C \text { or } G \text { or } T) \\
& D=\operatorname{not} C(A \text { or } G \text { or } T) \\
& H=\operatorname{not} G(A \text { or } C \text { or } T) \\
& V=\operatorname{not} T(A \text { or } C \text { or } G) \\
& \mathbf{N}=\mathbf{A} \text { or } \mathbf{C} \text { or } \mathbf{G} \text { or } \mathbf{T}
\end{aligned}
$$

Recognition sequences are written from $5^{\prime} \rightarrow 3^{\prime}$, only one strand being given, and the point of cleavage is indicated by an arrow ( () . When no arrow appears, the precise cleavage site has not been determined. For example, AlCATGT is an abbreviation for

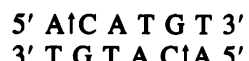

3' T G T A C†A 5'

For enzymes such as Bce83I and BsrDI, which cleave away from their recognition sequences, the sites of cleavage are indicated in parentheses.

For example Bce83I CTTGAG(16/14) indicates cleavage as shown below

$$
\text { 5'CTTGAGNNNNNNNNNNNNNNNN } 3^{\prime}
$$

3'GAACTCNNNNNNNNNNNNNN $15^{\prime}$

BsrDI GCAATG(2/0) indicates cleavage as shown below

5'GCAATGNN 3' $^{\prime}$

3'CGTTAC ' $^{\prime}$

In all cases the recognition sequences are oriented so that the cleavage sites lie on their $3^{\prime}$ side.

$A$ is $N^{6}$-methyladenosine. ${ }^{*}$ is $C^{5}$-methylcytosine. $C$ is $N^{4}$-methylcytosine.

Table 2.

\section{Type I enzymes}

$\begin{array}{lll}\begin{array}{l}\text { Prototype enzyme } \\ \text { CfrAI }\end{array} & \begin{array}{l}\text { Recognition sequence }^{2} \\ \text { GCANNNNNNNNGTGG }\end{array} & \text { Me site }^{3} \\ E c o A I & \text { GAGNNNNNNNGTCA } & 2(6),-3(6) \\ E c o B I & \text { TGANNNNNNNTGCT } & 3(6),-4(6) \\ E c o D I & \text { TTANNNNNNNGTCY } & \\ E c o D R 2 I & \text { TCANNNNNNGTCG } & \\ E c o D R 3 I & \text { TCANNNNNNNATCG } & \\ E c o D X X I & \text { TCANNNNNNNRTTC } & \\ E c o \text { EI } & \text { GAGNNNNNNNATGC } & \\ E c o K I & \text { AACNNNNNNGTGC } & 2(6),-3(6) \\ E c o R 124 I & \text { GAANNNNNNRTCG } & \\ E c o R 124 / 3 I & \text { GAANNNNNNNRTCG } & -3(6) \\ E c o R D 2 I & \text { GAANNNNNNRTTC } & \end{array}$


Nucleic Acids Research, 1993, Vol. 21, No. 133131

Table 2. (continued)

\begin{tabular}{lll}
\hline EcoRD3I & GAANNNNNNNRTTC & \\
StySBI & GAGNNNNNNRTAYG & $2(6),-3(6)$ \\
StySII & GAGNNNNNNGTRC & \\
StySPI & AACNNNNNNGTRC & $2(6),-3(6)$ \\
StySQI & AACNNNNNNRTAYG &
\end{tabular}

Type III enzymes

$\begin{array}{lll}\text { Prototype enzyme } & \text { Recognition sequence } & \text { Me }^{2} \\ \text { EcoPI } & \text { AGACC } & 3(6) \\ \text { EcoP15I } & \text { CAGCAG (25/27) } & 5(6) \\ \text { HinfIII } & \text { CGAAT } & \\ \text { StyLTI } & \text { CAGAG } & 4(6)\end{array}$

Type II enzymes

\begin{tabular}{|c|c|c|c|c|}
\hline $\begin{array}{l}\text { Prototype }^{1} \\
\text { enzyme }\end{array}$ & Isoschizomers & $\begin{array}{l}\text { Recognition }{ }^{2} \\
\text { Sequence }\end{array}$ & $\mathrm{Me}^{3}$ site & $\begin{array}{l}\text { Commercial }^{4} \\
\text { source }\end{array}$ \\
\hline Aat $\Pi \amalg$ & & GACGTIC & & ELMNOPRSUX \\
\hline$A c c \mathrm{I}$ & & GT MKAC & & ABDEGKLMNOPQRSUX \\
\hline AciI & & $\operatorname{CCGC}(-3 /-1)$ & & $\mathbf{N}$ \\
\hline \multirow[t]{2}{*}{ AclI } & & AAICGTT & & \\
\hline & Psp1406I & AAtCGTT & & FMN \\
\hline \multirow[t]{4}{*}{ AcyI } & & GRICGYC & & MR \\
\hline & $B b i I I$ & GRICGYC & & AK \\
\hline & BsaHI & GRICGYC & & BNS \\
\hline & Hin $1 \mathrm{I}$ & GRICGYC & & DEFOU \\
\hline \multirow{2}{*}{$A f l I I$} & & CITTAAG & & ABKNOSUX \\
\hline & BfrI & C†TTAAG & & $\mathbf{M}$ \\
\hline AflIII & & AtCRYGT & & BMNIT \\
\hline \multirow{2}{*}{ AgeI } & & AłCCGGT & & $\mathbf{N}$ \\
\hline & $\operatorname{PinAI}$ & AłCCGGT & & BM \\
\hline \multirow[t]{2}{*}{ AhaIII } & & TTT†AAA & & \\
\hline & DraI & TTT\AAA & & ABDEFGKLMNOPQRSUX \\
\hline AluI & & AGtCT & $3(5)$ & ABDEFGHKLMNOPQRSUX \\
\hline$A l w \mathrm{NI}$ & & CAGNNNICTG & & BNSU \\
\hline \multirow[t]{2}{*}{ ApaI } & & GGGCCtC & $4(5)$ & BEGKLMNOPRSUX \\
\hline & Bsp120I & GIGGCCC & & DFN \\
\hline ApaBI & & GCANNNNN $\uparrow T G C$ & & \\
\hline \multirow[t]{2}{*}{ ApaLI } & & GITGCAC & & DEKNSUX \\
\hline & Alw44I & GITGCAC & & BFMORU \\
\hline ApoI & & R†AATTY & & $\mathbf{N}$ \\
\hline AscI & & GGICGCGCC & & $\mathbf{N}$ \\
\hline \multirow{5}{*}{ AsuI } & & GIGNCC & & \\
\hline & BsiZI & GiGNCC & & W \\
\hline & Bsu54I & GIGNCC & & W \\
\hline & Cfr13I & GIGNCC & $4(5)$ & DFKOU \\
\hline & Sau96I & GIGNCC & $4(5)$ & BLMNORSUX \\
\hline \multirow[t]{8}{*}{ AsuII } & & TTICGAA & & $\mathrm{X}$ \\
\hline & BsiCI & TTICGAA & & EUW \\
\hline & Bsp119I & TTICGAA & & DF \\
\hline & BstBI & TTICGAA & & NS \\
\hline & Csp45I & TTICGAA & & ORU \\
\hline & $L s p \mathrm{I}$ & TTICGAA & & $\mathrm{L}$ \\
\hline & $N s p \mathrm{~V}$ & TTICGAA & & ABKOP \\
\hline & SfuI & TTICGAA & & $\mathbf{M}$ \\
\hline \multirow[t]{4}{*}{ AvaI } & & CIYCGRG & & ABEGKLMNOPRSUX \\
\hline & BcoI & C†YCGRG & & W \\
\hline & Eco88I & C†YCGRG & & $\mathrm{DF}$ \\
\hline & Nli387/7I & CYCGRIG & & \\
\hline \multirow{4}{*}{ AvaII } & & GIGWCC & & ABEGKMNPRSX \\
\hline & $E c 047 \mathrm{I}$ & GIGWCC & & DFOU \\
\hline & MspAI & GGWCC & & $\mathrm{N}$ \\
\hline & $\operatorname{SinI}$ & G†GWCC & $4(5)$ & LRS \\
\hline \multirow[t]{6}{*}{ AvaIII } & & ATGCAT & & \\
\hline & BfrBI & ATGICAT & & \\
\hline & EcoT22I & ATGCAIT & & KOU \\
\hline & Mph1103I & ATGCAIT & & $\mathbf{F}$ \\
\hline & NsiI & ATGCAIT & & BDELMNRSX \\
\hline & Ppu10I & AłTGCAT & & DFN \\
\hline \multirow{2}{*}{ AvrII } & & C†CTAGG & & $\mathbf{N}$ \\
\hline & $B \ln \mathrm{I}$ & CICTAGG & & $\mathbf{K}$ \\
\hline
\end{tabular}


3132 Nucleic Acids Research, 1993, Vol. 21, No. 13

Table 2. (continued)

\begin{tabular}{|c|c|c|c|c|}
\hline \multirow{3}{*}{$\begin{array}{l}\text { BaeI } \\
\text { BalI }\end{array}$} & & ACNNNNGTAYC & & \\
\hline & & TGGICCA & $4(5)$ & AKRX \\
\hline & MscI & TGGICCA & & BDNOSU \\
\hline BamHI & & $\begin{array}{l}\text { GIGATCC } \\
\text { GIGATCC }\end{array}$ & $5(4)$ & $\begin{array}{l}\text { ABDEFGHKLMNOPQRSUWX } \\
\text { P }\end{array}$ \\
\hline$B b v I$ & Bsti & GCAGC (8/12) & $2(5),-2(5)$ & ENX \\
\hline \multirow[t]{4}{*}{ BbvII } & Bst71I & $\begin{array}{l}\text { GCAGC }(8 / 12) \\
\text { GAAGAC }(2 / 6)\end{array}$ & & $\mathbf{R}$ \\
\hline & BbsI & GAAGAC (2/6) & & NU \\
\hline & BpuAI & GAAGAC (2/6) & & $\mathbf{M}$ \\
\hline & Bsc91I & GAAGAC (2/6) & & $\mathbf{R}$ \\
\hline$B c c I$ & & CCATC & & \\
\hline $\begin{array}{l}\text { Bce83I } \\
\text { Bcefl }\end{array}$ & & $\begin{array}{l}\text { CTTGAG (16/14) } \\
\text { ACGGC (12/13) }\end{array}$ & & \\
\hline$B c g I^{5}$ & & GCANNNNNNTCG $(12 / 10)$ & & NU \\
\hline \multirow{3}{*}{ BcII } & & TIGATCA & & BDEFGLMNOPRSUX \\
\hline & BsiQI & TIGATCA & & W \\
\hline & FbaI & TIGATCA & & $\mathbf{K}$ \\
\hline \multirow[t]{2}{*}{ BetI } & & WICCGGW & & \\
\hline & BsaWI & WICCGGW & & $\mathbf{N}$ \\
\hline BglI & & GCCNNNNINGGC & & ABDEFGHLMNOPQRSUWX \\
\hline \multirow[t]{2}{*}{$\begin{array}{l}\text { BglII } \\
\text { BinI }\end{array}$} & & $\begin{array}{l}\text { AlGATCT } \\
\text { GGATC }(4 / 5)\end{array}$ & & ABDEFGHKLMNOPQRSUWX \\
\hline & $A l w \mathrm{I}$ & GGATC (4/5) & & NSU \\
\hline $\begin{array}{l}\text { Bpu10I } \\
\text { BsaAI }\end{array}$ & & CCTNAGC $(-5 /-2)$ & & \\
\hline BsaAI & & YACIGTR & & NU \\
\hline \multirow[t]{4}{*}{ BsaBI } & & GATNNINNATC & & NU \\
\hline & Bsh1365I & GATNNINNATC & & $\mathbf{F}$ \\
\hline & BsiBI & GATNNINNATC & & W \\
\hline & MamI & GATNNINNATC & & $\mathbf{M}$ \\
\hline \multirow{3}{*}{$\begin{array}{l}\text { BscGI } \\
\text { BsePI }\end{array}$} & & CCCGT & & \\
\hline & & GCGCGC & & \\
\hline & BssHIII & GICGCGC & & BDEKLMNOQRUX \\
\hline \multirow{2}{*}{$\begin{array}{l}\text { BsgI } \\
\text { BsiI }\end{array}$} & & $\begin{array}{l}\text { GAGGAG } \\
\text { GTGCAG (16/14) }\end{array}$ & & \\
\hline & & $\begin{array}{l}\text { GTGCAG (16/14) } \\
\text { CTCGTG }(-5 /-1)\end{array}$ & & $\mathbf{N}$ \\
\hline \multirow[t]{2}{*}{ BsiYI } & & CCNNNNNINNGG & & MUW \\
\hline & BsII & CCNNNNNINNGG & & $\mathbf{N}$ \\
\hline BsmI & & GAATGC $(1 /-1)$ & & BDELMNOSUX \\
\hline & BsaMI & GAATGC $(1 /-1)$ & & $\mathbf{R}$ \\
\hline & $\mathrm{BscCI}$ & GAATGC $(1 /-1)$ & & $\mathbf{W}$ \\
\hline & Mva1269I & GAATGC $(1 /-1)$ & & $\mathbf{F}$ \\
\hline BsmAI & & GTCTC (1/5) & & NU \\
\hline & Alw26I & GTCTC (1/5) & $3(5),-4(6)$ & DFR \\
\hline Bsp1407I & & TIGTACA & & FN \\
\hline & BsrGI & TIGTACA & & $\mathbf{N}$ \\
\hline & SspBI & TIGTACA & & $\mathbf{M}$ \\
\hline BspGI & & CTGGAC & & \\
\hline BspHI & & T†CATGA & & NSU \\
\hline & RcaI & TICATGA & & BM \\
\hline BspLU11I & & AICATGT & & \\
\hline BspMI & & ACCTGC (4/8) & & $\mathbf{N}$ \\
\hline BspMII & & TICCGGA & & $\mathbf{X}$ \\
\hline & AccIII & TICCGGA & & EKQR \\
\hline & BseAI & TICCGGA & & $\mathbf{M}$ \\
\hline & BsiMI & TICCGGA & & $\mathbf{W}$ \\
\hline & Bsp13I & TICCGGA & & L \\
\hline & BspEI & T1CCGGA & & NS \\
\hline & Bsu23I & TICCGGA & & W \\
\hline & Kpn2I & TICCGGA & & BDFS \\
\hline & MroI & TiCCGGA & & MOU \\
\hline BsrI & & ACTGG $(1 /-1)$ & & NU \\
\hline & BseNI & ACTGG $(1 /-1)$ & & DF \\
\hline BsrBI & & GAGCGG $(-3 /-3)$ & & $\mathbf{N}$ \\
\hline BsrDI & & GCAATG $(2 / 0)$ & & $\mathbf{N}$ \\
\hline BstEII & & GIGTNACC & & BGHLMNOPQRSUX \\
\hline & BstPI & GIGTNACC & & $\mathbf{K}$ \\
\hline & $\begin{array}{l}E \cos 91 \mathrm{I} \\
E \operatorname{co065I}\end{array}$ & $\begin{array}{l}\text { GIGTNACC } \\
\text { GIGTNACC }\end{array}$ & & $\mathrm{DF}$ \\
\hline BstXI & & $\begin{array}{l}\text { GIGTNACC } \\
\text { CCANNNNNINTGG }\end{array}$ & & K \\
\hline Cac8I & & GCNINGC & & BDEGHKLMNOQRSUX \\
\hline CauII & & CCtSGG & & \\
\hline & BcnI & CCISGG & $2(4)$ & DFK \\
\hline
\end{tabular}


Nucleic Acids Research, 1993, Vol. 21, No. 133133

Table 2. (continued)

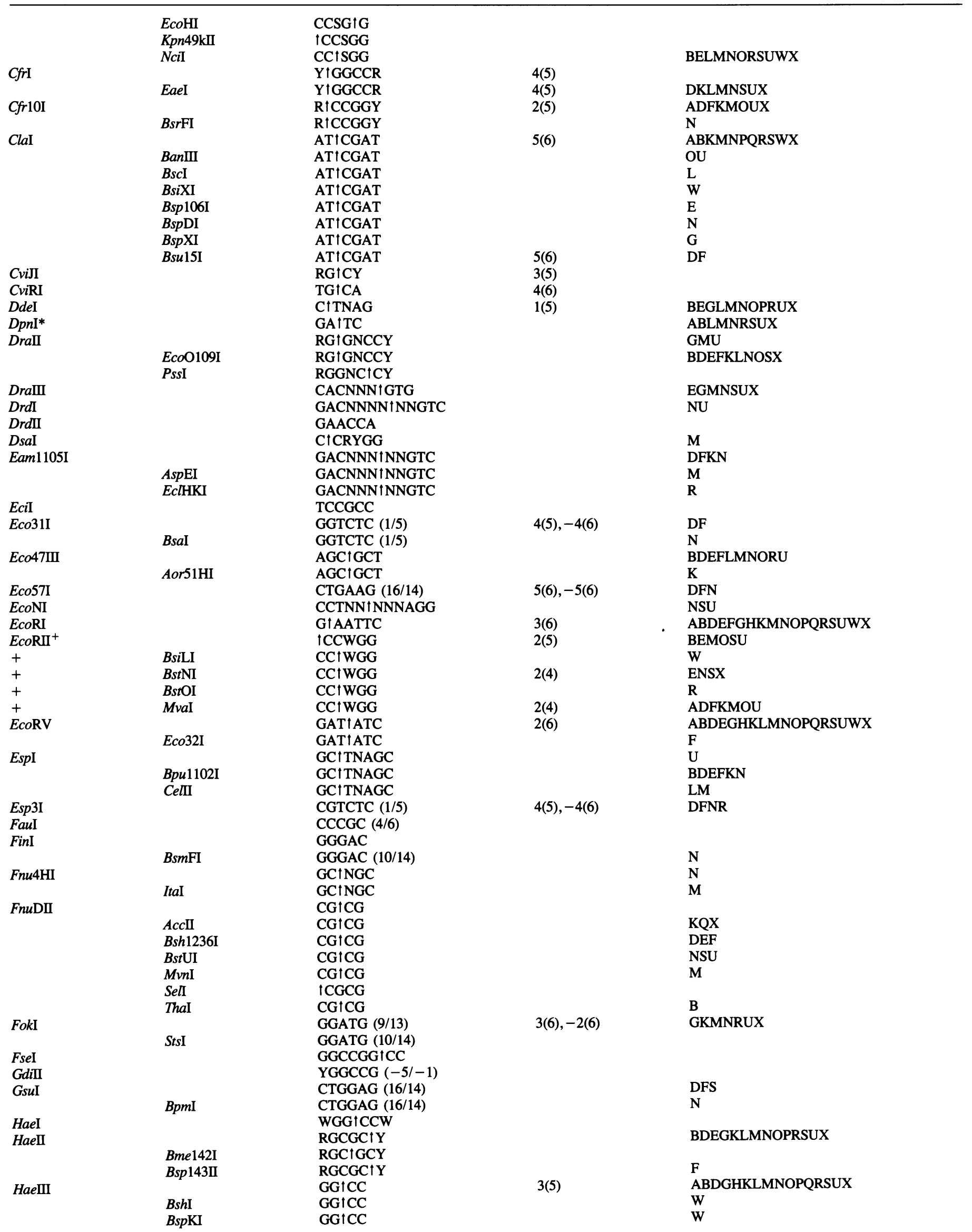


3134 Nucleic Acids Research, 1993, Vol. 21, No. 13

Table 2. (continued)

\begin{tabular}{|c|c|c|c|c|}
\hline & $\begin{array}{l}\text { BsuRI } \\
\text { PalI }\end{array}$ & $\begin{array}{l}\text { GGtCC } \\
\text { GG†CC }\end{array}$ & $3(5)$ & $\begin{array}{l}\text { F } \\
\text { EP }\end{array}$ \\
\hline HgaI & & GACGC $(5 / 10)$ & $3(5),-2(5)$ & NSUX \\
\hline HgiAI & & GWGCW1C & & NX \\
\hline & Alw21I & GWGCWIC & & BDF \\
\hline & AspHI & GWGCWIC & & $\mathbf{M}$ \\
\hline \multirow{3}{*}{$\mathrm{HgiCI}$} & BsiHKAI & GWGCWtC & & $\mathbf{N}$ \\
\hline & & GIGYRCC & $?(5)$ & \\
\hline & BanI & GIGYRCC & $?(5)$ & EMNOPRSUX \\
\hline HgiEII & Eco64I & $\begin{array}{l}\text { G†GYRCC } \\
\text { ACCNNNNNNGGT }\end{array}$ & & DF \\
\hline \multirow[t]{3}{*}{ HgiJII } & & GRGCY IC & & 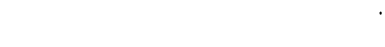 \\
\hline & BanII & GRGCY & & BKLMNOPRSUX \\
\hline & Eco24I & GRGCY†C & & DF \\
\hline \multirow[t]{4}{*}{ HhaI } & & GCG†C & $2(5)$ & BGKNOPRSUX \\
\hline & CfoI & GCGIC & & BLMRS \\
\hline & Hin6I & GtCGC & & DF \\
\hline & HinP1I & $\begin{array}{l}\text { GICGC } \\
\text { GTY†RAC }\end{array}$ & & $\begin{array}{l}\text { NSX } \\
\text { EM }\end{array}$ \\
\hline HindII & HincII & $\begin{array}{l}\text { GTY†RAC } \\
\text { GTY†RAC }\end{array}$ & $\begin{array}{l}5(6) \\
5(6)\end{array}$ & $\begin{array}{l}\text { EM } \\
\text { ABDFGHKLNOPORSUX }\end{array}$ \\
\hline HindIII & & $\begin{array}{l}\text { GTY†RAC } \\
\text { AłAGCTT }\end{array}$ & $\begin{array}{l}5(6) \\
1(6)\end{array}$ & $\begin{array}{l}\text { ABDFGHKLNOPQRSUX } \\
\text { ABDEFGHKLMNOPORSUWX }\end{array}$ \\
\hline Hinfl & & GIANTC & & ABDEFGHKLMNOPQRSUWX \\
\hline HpaI & & GTTtAAC & $5(6)$ & ABDEFGKLMNOPQRSUX \\
\hline \multirow[t]{3}{*}{ Hpall } & & C†CGG & $2(5)$ & ABDEFGLMNOPQRSUX \\
\hline & HapII & C†CGG & $2(5)$ & $\mathbf{K}$ \\
\hline & MspI & CtCGG & $1(5)$ & ABDEFGHKLMNOPQRSUWX \\
\hline HphI & & GGTGA (8/7) & $-2(5)$ & NSUX \\
\hline \multirow[t]{3}{*}{ KpnI } & & GGTACIC & $4(6)$ & ABDEFGHKLMNOPQRSUWX \\
\hline & Acc65I & GIGTACC & & DFNR \\
\hline & Asp718I & GIGTACC & & $\mathbf{M}$ \\
\hline \multirow[t]{3}{*}{ Ksp632I } & & CTCTTC (1/4) & & $\mathbf{M}$ \\
\hline & Eam1104I & CTCTTC (1/4) & & DF \\
\hline & EarI & CTCTTC (1/4) & & NU \\
\hline \multirow[t]{2}{*}{ MaeI } & & CtTAG & & $\mathbf{M}$ \\
\hline & Bfal & C†TAG & & $\mathbf{N}$ \\
\hline $\begin{array}{l}\text { Maell } \\
\text { MaeIII }\end{array}$ & & AICGT & & $\mathbf{M}$ \\
\hline $\mathrm{Mbol}^{7}$ & & $\begin{array}{l}\text { IGTNAC } \\
\text { IGATC }\end{array}$ & & M \\
\hline \multirow{3}{*}{+} & Bsp143I & IGATC & & $\begin{array}{l}\text { BEFGKNQRSX } \\
\text { F }\end{array}$ \\
\hline & DpnII & IGATC & $2(6)$ & NU \\
\hline & NdeII & tGATC & & BDM \\
\hline \multirow{6}{*}{$\begin{array}{l}+ \\
\text { MboII } \\
\text { McrI }\end{array}$} & Sau3AI & IGATC & $4(5)$ & ABDEGHKLMNOPQRSUX \\
\hline & & GAAGA (8/7) & $5(6)$ & BDFKNOQRSUX \\
\hline & & CGRYICG & & $\mathbf{M}$ \\
\hline & BsaOI & CGRYICG & & $\mathbf{R}$ \\
\hline & Bsh1285I & CGRY†CG & & DF \\
\hline & BsiEI & CGRYICG & & NW \\
\hline \multirow[t]{2}{*}{ MfeI } & & C†AATTG & & \\
\hline & MunI & C†AATTG & $3(6)$ & BDEFKMN \\
\hline \multirow{6}{*}{$\begin{array}{l}\text { MluI } \\
\text { MhyI } \\
\text { MmeI } \\
\text { MnII } \\
\text { MseI }\end{array}$} & & AICGCGT & & ABDEFGKLMNOPQRSUWX \\
\hline & & $\begin{array}{l}\text { GACTC (5/5) } \\
\text { TCCRAC (20/18) }\end{array}$ & & \\
\hline & & CCTC $(7 / 6)$ & & ENQUX \\
\hline & & T†TAA & & BNS \\
\hline & TrulI & T†TAA & & $\mathbf{F}$ \\
\hline & Tru9I & TITAA & & LMR \\
\hline \multirow{5}{*}{$\begin{array}{l}\text { MsII } \\
\text { MstI }\end{array}$} & & CAYNNINNRTG & & $\mathbf{N}$ \\
\hline & & TGCIGCA & & $\mathbf{x}$ \\
\hline & AviII & TGC†GCA & & $\mathbf{M}$ \\
\hline & FdiII & TGCIGCA & & $\mathbf{U}$ \\
\hline & FspI & TGCtGCA & & BKNOSU \\
\hline MwoI & & GCNNNNN $\$ NNGC & & $\mathbf{N}$ \\
\hline NaeI & BspWI & GCNNNNN†NNGC & & $\mathbf{M}$ \\
\hline Noel1 & NgoMI & $\begin{array}{l}\text { GCC } \uparrow G G C \\
\text { GiCCGGC }\end{array}$ & & DEKLMNOUX \\
\hline NarI & & $\begin{array}{l}\text { GICCGGC } \\
\text { GGtCGCC }\end{array}$ & & $\begin{array}{l}\text { N } \\
\text { pronopdety }\end{array}$ \\
\hline & BbeI & GGCGClC & & $\begin{array}{l}\text { BEMNOPRSUX } \\
\mathrm{K}\end{array}$ \\
\hline & EheI & GGCIGCC & & $\begin{array}{l}\mathbf{K} \\
\text { DFOU }\end{array}$ \\
\hline & KasI & GIGCGCC & & $\mathbf{N}$ \\
\hline $\begin{array}{l}\text { NcoI } \\
\text { NdeI }\end{array}$ & & CiCATGG & & ABDEFGHKLMNOPQRSUWX \\
\hline $\begin{array}{l}\text { NdeI } \\
\text { NheI }\end{array}$ & & CA†TATG & $4(6)$ & BDEFGKIMNPRSUX \\
\hline $\begin{array}{l}\text { Nhei } \\
\text { NhaIII }\end{array}$ & & $\begin{array}{l}\text { GICTAGC } \\
\text { CATG } \uparrow\end{array}$ & & BDEFGKIMNOPRSUX \\
\hline
\end{tabular}


Nucleic Acids Research, 1993, Vol. 21, No. 133135

Table 2. (continued)

\begin{tabular}{|c|c|c|c|c|}
\hline & CviAII & $\mathrm{C}$ ATG & $2(6)$ & \\
\hline \multirow[t]{2}{*}{ NlaIV } & & GGNINCC & & NSU \\
\hline & BscBI & GGN & & W \\
\hline NotI & & GCIGGCCGC & & ABDEFGKLMNOPQRSUWX \\
\hline \multirow[t]{2}{*}{$\begin{array}{l}\text { Not1 } \\
\text { NruI }\end{array}$} & & TCG 1 CGA & & BDEGKLMNOPQRSUWX \\
\hline & Bsp68I & TCGICGA & & $\mathbf{F}$ \\
\hline \multirow{3}{*}{$\begin{array}{l}\text { NspI } \\
N s p \text { BII }\end{array}$} & & RCATGIY & & ABKMU \\
\hline & & CMGICKG & & $\mathbf{U}$ \\
\hline & MspA1I & CMGICKG & & $\mathbf{R}$ \\
\hline $\begin{array}{l}\text { PacI } \\
\text { Pfl1108I }\end{array}$ & & $\begin{array}{l}\text { TTAAT } † \text { TAA } \\
\text { TCGTAG }\end{array}$ & & NU \\
\hline \multirow[t]{4}{*}{ PflMI } & & CCANNNN $\ N T G G$ & & NSU \\
\hline & $A c c \mathrm{~B} 7 \mathrm{I}$ & CCANNNNINTGG & & $\mathbf{R}$ \\
\hline & Esp1396I & CCANNNNINTGG & & $\mathbf{F}$ \\
\hline & Van91I & CCANNNNINTGG & & DFM \\
\hline \multirow{5}{*}{$\begin{array}{l}\text { PleI } \\
\text { PmaCI }\end{array}$} & & GAGTC $(4 / 5)$ & & $\mathbf{N}$ \\
\hline & & CAC†GTG & & AK \\
\hline & BbrPI & CACiGTG & & $\mathbf{M}$ \\
\hline & Eco72I & CACIGTG & & DEFR \\
\hline & PmII & CACIGTG & & $\mathbf{N}$ \\
\hline \multirow{3}{*}{$\begin{array}{l}\text { PmeI } \\
\text { PpuMI }\end{array}$} & & GTTTIAAAC & & $\mathbf{N}$ \\
\hline & & RGIGWCCY & & NSU \\
\hline & Psp5II & RGIGWCCY & & BDF \\
\hline \multirow{6}{*}{$\begin{array}{l}\text { PshAI } \\
\text { PstI } \\
\text { PvuI }\end{array}$} & & GACNNINNGTC & & $\mathbf{K}$ \\
\hline & & CTGCAIG & $5(6)$ & ABDEFGHKLMNOPORSUWX \\
\hline & & CGATICG & & ABDEFGKLMNOPQRSUX \\
\hline & Afa22MI & CGAITCG & & \\
\hline & BspCI & CGATICG & & E \\
\hline & XorII & CGATICG & & BS \\
\hline \multirow{4}{*}{$\begin{array}{l}\text { PvuII } \\
\text { RleAI } \\
\text { RsaI }\end{array}$} & & $\begin{array}{l}\text { CAG†CTG } \\
\text { CCCACA (12/9) }\end{array}$ & $4(4)$ & ABDEFGHKLMNOPQRSUWX \\
\hline & & GTIAC & & ABDEGLMNOPORSUWX \\
\hline & AfaI & GT $\uparrow A C$ & & $\mathrm{~K}$ \\
\hline & Csp6I & G†TAC & & DFN \\
\hline \multirow[t]{3}{*}{ RsrII } & & CGIGWCCG & & BMNSUX \\
\hline & CpoI & CGIGWCCG & & DFK \\
\hline & CspI & CGIGWCCG & & EORU \\
\hline \multirow[t]{4}{*}{ SacI } & & GAGCTIC & & AEGHKLMNOPQRSUWX \\
\hline & Ecl136II & GAGICTC & & DFN \\
\hline & EcoICRI & GAGICTC & & $\mathbf{R}$ \\
\hline & SstI & GAGCTIC & & BS \\
\hline SacII & & CCGCIGG & & EGHLNOPQRSUX \\
\hline & Cfr42I & CCGCIGG & & DF \\
\hline & KspI & CCGCIGG & & $\mathbf{M}$ \\
\hline & Mlu113I & CCIGCGG & & \\
\hline & SstII & CCGCIGG & & BS \\
\hline Sall & & GITCGAC & & ABDEFGHKLMNOPQRSUWX \\
\hline SapI & & GCTCTTC (1/4) & & $\mathbf{N}$ \\
\hline SauI & & CCITNAGG & & $\mathbf{M}$ \\
\hline & Bsu36I & CCITNAGG & & ENRS \\
\hline & ConI & CCITNAGG & & BS \\
\hline & Eco81I & CCITNAGG & & DFKOU \\
\hline & MstII & CCITNAGG & & $\mathrm{X}$ \\
\hline ScaI & & AGT†ACT & & ABDEFGKLMNOPQRSUX \\
\hline ScrFI & & CCiNGG & & DMNOSUX \\
\hline & DsaV & ICCNGG & & $\mathbf{M}$ \\
\hline SduI & & GDGCHIC & & $\mathbf{F}$ \\
\hline & $B m y I$ & GDGCHIC & & $\mathbf{M}$ \\
\hline & Bsp1286I & GDGCHIC & & DKNRUX \\
\hline SecI & & C†CNNGG & & \\
\hline & BsaJI & CICNNGG & & BNU \\
\hline SexAI & & AICCWGGT & & $\mathbf{M}$ \\
\hline SfaNI & & GCATC $(5 / 9)$ & & NSX \\
\hline & BscAI & GCATC $(4 / 6)$ & & \\
\hline SfeI & & CITRYAG & & \\
\hline & SfcI & C†TRYAG & & $\mathbf{N}$ \\
\hline SfiI & & GGCCNNNNINGGCC & & ABDEGLMNOPQRSUX \\
\hline SgrAI & & CR†CCGGYG & & $\mathrm{M}$ \\
\hline SmaI & & CCCIGGG & $2(4)$ & ABDEFGHKLMNOPQRSUWX \\
\hline & Cfr9I & C†CCGGG & $2(4)$ & DFOU \\
\hline & PspAI & CiCCGGG & & $\mathbf{E}$ \\
\hline & $X m a I$ & C†CCGGG & & NRSUWX \\
\hline SnaI & & GTATAC & & \\
\hline
\end{tabular}


3136 Nucleic Acids Research, 1993, Vol. 21, No. 13

Table 2. (continued)

\begin{tabular}{|c|c|c|c|c|}
\hline & BspM90I & GTAITAC & & W \\
\hline & Bst11071 & GTAITAC & & DFKMN \\
\hline \multirow[t]{2}{*}{ SnaBI } & & TAC $\uparrow$ GTA & & EKLMNRSX \\
\hline & Eco105I & TACIGTA & & BDFOU \\
\hline \multirow{4}{*}{$\begin{array}{l}\text { SpeI } \\
\text { SphI }\end{array}$} & & AtCTAGT & & BDEKLMNORSUWX \\
\hline & & GCATGIC & & ABDEGHKLMNOPQRSUX \\
\hline & $B b u I$ & GCATGIC & & $\mathbf{R}$ \\
\hline & PaeI & GCATGIC & & $\mathbf{F}$ \\
\hline \multirow[t]{4}{*}{ SplI } & & C†GTACG & & AK \\
\hline & BsiWI & C†GTACG & & MNUW \\
\hline & Pf23II & C†GTACG & & DF \\
\hline & SunI & C†GTACG & & B \\
\hline Srfi & & GCCC $1 G G G C$ & & EO \\
\hline Sse8387I & & CCTGCAIGG & & $\mathbf{K}$ \\
\hline SspI & & AATIATT & & BDEFKLMNORUX \\
\hline \multirow[t]{3}{*}{ StuI } & & AGGICCT & & ABEGKLMNPQRSX \\
\hline & AatI & AGGICCT & & OU \\
\hline & Eco147I & AGGICCT & & DF \\
\hline \multirow[t]{3}{*}{ StyI } & & CICWWGG & & BEMNRSX \\
\hline & Eco130I & ClCWWGG & & DFU \\
\hline & EcoT14I & ClCWWGG & & AK \\
\hline SwaI & & ATTTIAAAT & & $\mathbf{M}$ \\
\hline \multirow{2}{*}{ TaqI } & & TICGA & $4(6)$ & ABDEFGLMNOPQRSUWX \\
\hline & TthHB8I & TICGA & $4(6)$ & $\mathrm{K}$ \\
\hline $\operatorname{Taq} \Pi^{8}$ & & $\begin{array}{l}\text { CACCCA (11/9) } \\
\text { GACCGA (11/9) }\end{array}$ & & \\
\hline \multirow{4}{*}{$\begin{array}{l}\text { TfiI } \\
\text { Tsp45I } \\
\text { TspEI }\end{array}$} & & G†AWTC & & NU \\
\hline & & GTSAC & & \\
\hline & & AATT & & \\
\hline & Tsp509I & †AATT & & $\mathbf{N}$ \\
\hline \multirow[t]{2}{*}{ Tth111I } & & GACN $\ N N G T C$ & & DKNPQRUX \\
\hline & AspI & GACNINNGTC & & $\mathbf{M}$ \\
\hline \multirow{4}{*}{$\begin{array}{l}\text { Tth111II } \\
\text { VspI }\end{array}$} & & CAARCA (11/9) & & \\
\hline & & ATITAAT & & BDEFKR \\
\hline & AseI & AT†TAAT & & NOSU \\
\hline & AsnI & ATITAAT & & $\mathbf{M}$ \\
\hline \multirow{6}{*}{$\begin{array}{l}\text { XbaI } \\
X c m I \\
X h o I\end{array}$} & & TICTAGA & $6(6)$ & ABDEFGHKLMNOPQRSUWX \\
\hline & & CCANNNNN $\ N N N N T G G$ & & NU \\
\hline & & CITCGAG & & ADEFGHKLMNOPQRSUWX \\
\hline & CcrI & C†TCGAG & & $\mathrm{X}$ \\
\hline & PaeR7I & C†TCGAG & $5(6)$ & NSX \\
\hline & SciI & CTCiGAG & & \\
\hline \multirow[t]{3}{*}{ Xholl } & & RIGATCY & & EMRX \\
\hline & Bst YI & R†GATCY & & BNU \\
\hline & $M f l I$ & RIGATCY & & AK \\
\hline \multirow[t]{5}{*}{ XmaIII } & & CIGGCCG & $4(5)$ & $\mathbf{B E}$ \\
\hline & BstZI & C†GGCCG & & $\mathbf{R}$ \\
\hline & EagI & CtGGCCG & & NS \\
\hline & $E c I X I$ & C†GGCCG & & $\mathbf{M}$ \\
\hline & Eco52I & C†GGCCG & & DFKORU \\
\hline \multirow[t]{2}{*}{$X m n I$} & & GAANN $\ N N T T C$ & & DENX \\
\hline & Asp700I & GAANNINNTTC & & $\mathbf{M}$ \\
\hline
\end{tabular}

1. * signifies that DpnI requires the presence of 6-methyladenosine within the recognition sequence GATC.

2. Recognition sequence nomenclature is as in Table 1

3. The site of methylation by the cognate methylase when known is indicated as follows. The first number shows the base within the recognition sequence that is modified. A negative number indicates the complementary strand, numbered from the 5 ' base of that strand. The number in parentheses indicates the specific methylation involved. (6) = N6-methyladenosine; (5) = 5-methylcytosine; (4) = N4-methylcytosine.

4. Commercial sources of restriction enzymes are abbreviated as follows:

A Amersham (5/93)

B Life Technologies Inc, Gibco-BRL (4/93)

D Angewandte Gentechnologie Systeme (4/93)

E Stratagene (4/93)

F Fermentas MBI (4/93)

G Appligene (4/93)

H American Allied Biochemical, Inc. (5/93)

K Takara (5/93)

L Northumbria Biologicals Limited (4/93)

M Boehringer-Mannheim (4/93)

N New England BioLabs (5/93)

O Toyobo (5/93)

P Pharmacia P-L Biochemicals (5/93)

Q Molecular Biology Resources (4/93) 
R Promega Corporation (4/93)

S Sigma (4/93)

U United States Biochemical Corporation (4/93)

W International Laboratory Services (4/93)

$\mathrm{X}$ New York Biolabs (4/93)

The date in parentheses indicates the most recent update.

5. BcgI cleaves on both sides of the recognition sequence: 10 bases $5^{\prime}$ to the recognition sequence and 12 bases $3^{\prime}$ to it on both strands: Thus the recognition site is excised in a fragment, 34 base pairs long, with 2-base 3 '-extensions at each end.

6. EcoRII isoschizomers fall into two classes based upon their sensitivity to methylation. EcoRII will not cleave when the second cytosine in the recognition sequence is methylated to 5-methylcytosine whereas $M v a I$ will cleave such a sequence. Isoschizomers of $E c o R I I$ that are like $M v a I$ are indicated by + .

7. MboI isoschizomers fall into two classes based upon their sensitivity to methylation. MboI will not cleave when the recognition sequence contains 6-methyladenosine whereas Sau3AI will not cleave when its recognition sequence contains 5-methylcytosine. Isoschizomers of $M$ boI that are like Sau3AI are indicated by + .

8. TaqII differs from other restriction enzymes in recognizing two distinct sequences: GACCG and CACCCA. 